\title{
Erodibilidade e tensão crítica de cisalhamento em solos de estradas não pavimentadas
}

\author{
João F. de 0 liveira $^{1}$, N ori P. G riebeler ${ }^{1}$, Vladia Correchel ${ }^{1} \&$ Valtercides C. da Silva $^{1}$
}

\section{RESUMO}

\begin{abstract}
A fal ta de um sistema adequado para drenagem de águas pluviais em estradas não pavimentadas é um dos principais fatores que causam a sua degradação e, para que referidos sistemas possam ser adequadamente planejados e dimensionados é necessário o conhecimento de parâmetros de resistência dos solos. Com este trabal ho se teve, por objetivo, determinar a erodibilidade e a tensão crítica de cisalhamento para diferentes solos de estradas não pavimentadas. Utilizou-se um simulador de escoamento superficial instalado diretamente nos canais das estradas, sob condição natural e se determinou a perda de solo para diferentes lâminas de escoamento. A erodibilidade e a tensão crítica de cisal hamento foram determinadas por meio do ajuste de curvas relacionando-se a perda de solo em função da tensão cisalhante provocada pelo escoamento. 0 s resultados alcançados mostraram variações nos valores de erodibilidade e de tensão crítica de cisalhamento das estradas avaliadas. Os valores de erodibilidade encontrados mostraram, quando comparados com valores observados na literatura, elevada suscetibilidade à erosão para as condições de estradas, sendo mais elevados nos solos de textura mais arenosa e siltosa. Os valores de tensão crítica se mostraram bastante próximos aos observados em outros trabalhos.
\end{abstract}

Palavras-chave: erosão, estradas vicinais, modelo hidrológico

\section{Erodibility and critical shear stress on unpaved road soils}

\begin{abstract}
The absence of an adequate drainage system in unpaved roads is one of the main factors for their degradation. For adequate planning knowledge of the resistance parameters of soil is necessary. This study had as its objective the determinatiom of the erodibility and critical shear stress of unpaved road soils. For this work, a runoff simulator was directly installed on road channels, under natural conditions. Different flow depths were applied and the soil loss was measured for each depth. The erodibility and the critical shear stress were determined through adjusted curves relating soil disaggregation and flow shear stress. The results showed variations in erodibility and in critical shear stress values of the roads. The erodibility values obtained, when compared with values observed in the literature, evidenced high susceptibility to the erosion for road conditions. These values were higher on silt loam and sandy soils. The critical shear stress values were similar to those observed in other publications.
\end{abstract}

Key words: erosion, earth roads, runoff simulator

\footnotetext{
${ }^{1}$ EA/UFG, Rodovia Goiânia-Nova Veneza, Km Zero, Campus Samambaia, CP 131, CEP 74001-970, Goiânia, G0. Fone (62) 3223-3013. E-mail: jfonseca105@hotmail.com; (62) 3521-1534. E-mail: griebeler@yahoo.com.br; (62) 3521-1539. E-mail: vladiacorrechel@hotmail.com; (62) 3521-1534. E-mail: vcsilva@agro.ufg.br
} 


\section{INTRODUÇÃO}

A malha rodoviária de qualquer país é imprescindível para seus avanços econômico e social. As estradas não pavimentadas, ou vicinais, apresentam papel fundamental para a economia de um país e constituem a principal forma de transporte de alimentos do produtor aos centros consumidores. São essenciais, ainda, para o desenvolvimento social, uma vez que constituem as principais vias de acesso ao atendimento das necessidades de trabalho, saúde e educação de grande parte da população. Ambientalmente, também têm grande relevância, haja vista que interferem na paisagem natural, concentram o escoamento superficial constituindo, assim, fator de degradação.

De acordo com Griebeler et al. (2005a), os custos para construção e manutenção das estradas são bastante elevados, razão pela qual sua construção deve ser realizada de maneira a se considerar todos os fatores passíveis de prejudicar a sua estrutura. O solo é o material primário e único para construção de estradas não pavimentadas, servindo como pista de rolamento, material de suporte às cargas do transporte, fundação e para drenagem do escoamento superficial; neste sentido, a análise deve ser criteriosa uma vez que, para estradas não pavimentadas, o material do leito apresenta grande variabilidade sendo, normalmente, obtido no próprio local de construção da estrada.

É grande a extensão territorial do Brasil, em que a maior parte de sua área é regida por clima tropical de chuvas intensas, o que causa degradação de grandes áreas de terras, assoreamento de nascentes, lagos e rios. De acordo com Panachudi et al. (2006), a erosão hídrica é o processo de degradação do solo que mais tem afetado a capacidade produtiva dos solos, facilitada por interferência antrópica que, na maioria das vezes, resulta num processo de erosão acelerada.

Na erosão hídrica, a desagregação das partículas de solo na superfície é uma ação provocada pela energia de impacto das gotas da chuva e pela força cisalhante do escoamento superficial. O domínio da energia de impacto das gotas da chuva ou do escoamento superficial no desprendimento e transporte de sedimentos, depende se a erosão ocorre em sulcos ou em áreas entre sulcos (Amorim et al., 2001).

Os processos erosivos em áreas agrícolas têm merecido diversos estudos, no sentido da mitigação dos problemas enquanto que em áreas de estradas de terra o tema, pela extensão que representa, tem sido pesquisado de forma ainda tímida.

Durante o processo de precipitação as chuvas sofrem evaporação, infiltração, acumulação ou escoam superficialmente. Em estradas, mesmo nas não pavimentadas e devido à sua superfície compactada e quase impermeabilizada, uma pequena parcela da água da chuva é infiltrada e a maior parte escoada superficialmente. Este escoamento, devido à forma construtiva e à manutenção inadequada das estradas, ocorre normalmente pelo próprio leito, provocando sua degradação.

Para Campos \& Alves (2006), a ocorrência de grandes áreas impermeabilizadas e/ou a sistematização de terrenos associados à falta e/ou deficiência de um sistema de drenagem das águas pluviais, pode causar a desestabilização, queda de taludes e o aparecimento de processos erosivos de grandes dimensões.

Corrêa et al. (2006) ressaltam que, em estradas florestais, o principal problema ambiental é o desencadeamento de processos erosivos nas estradas, uma vez que estas funcionam como canais, transportando água e sedimentos, assoreando e poluindo mananciais.

O conhecimento das relações entre os fatores que causam as perdas de solo e os que permitem reduzi-las é de fundamental importância (Moreti et al., 2003). A determinação de parâmetros de tensão crítica de cisalhamento e a erodibilidade de diferentes solos que possibilitem a avaliação de sua resistência, juntamente com modelos de direcionamento e controle de drenagem em estradas não pavimentadas deve fazer parte de estudos que visem combater a erosão e proteger o meio ambiente.

De acordo com Nogami \& Villibor (1995), a erodibilidade do solo é um dos fatores mais importantes para a escolha do projeto mais apropriado a fim de controlar a erosão ao longo das rodovias; outro fator de grande significância para determinação da capacidade resistiva do solo a erosão, é a tensão crítica de cisalhamento a qual corresponde à máxima tensão que pode ser aplicada ao solo sem que haja remoção de suas partículas. Desta forma, se propôs neste trabalho, determinar a erodibilidade e a tensão crítica de cisalhamento para diferentes solos de estradas não pavimentadas.

\section{MATERIAL E MÉTODOS}

\section{Determinação da erodibilidade e tensão crítica de cisalhamento}

Para obtenção da erodibilidade e tensão crítica de cisalhamento do solo, desenvolveu-se um simulador de escoamento superficial cujo modelo consiste em um aperfeiçoamento do equipamento proposto por Griebeler et al. (2005b). O conjunto desenvolvido permite simular o escoamento diretamente nos canais das estradas em condição natural.

\section{Desenvolvimento do simulador de escoamento}

$\mathrm{O}$ equipamento construído se resume em um conjunto contendo caixas d'águas com volumes de 2.500 L (reservatório), $500 \mathrm{~L}$ (controle de nível) e três caixas de $300 \mathrm{~L}$ cada uma (armazenamento), ligadas por mangotes com diâmetros de 75, 25 e $100 \mathrm{~mm}$, respectivamente. O controle de escoamento é realizado por meio de registros que conectam as caixas d'água aos mangotes e permitem o controle da vazão a ser aplicada ao canal. A calha por onde ocorre o escoamento é construída em ferro, com $22 \mathrm{~cm}$ de largura por $210 \mathrm{~cm}$ de comprimento total, permitindo contato do escoamento com o solo em 0,20 $\mathrm{m}^{2}$; após a passagem da água pela calha ela é conduzida através de mangote, para o sistema composto das caixas de armazenamento, nas quais fica armazenada para posterior filtragem. Fazem parte, também, do simulador, peneiras com malha \#200 (0,074 mm), grades metálicas para apoio e nivelamento das caixas em diferentes situações de campo, além de outros materiais de consumo, como cronômetro, trena, GPS, espuma 
para vedação, bola de isopor, borracha, nível e régua de nivelamento.

O equipamento possibilita variar a vazão ao longo do tempo e, assim, aproximar o escoamento simulado daquele esperado para o canal. Cada variação na vazão pode ser acumulada em reservatório próprio, no sistema de armazenamento. Por meio da filtragem da água acumulada neste sistema é possível a determinação da quantidade de solo erodido para cada vazão aplicada.

\section{Realização de testes com o simulador de escoamento}

Para sua calibração, o equipamento foi montado, inicialmente, na Escola de Agronomia e Engenharia de Alimentos da Universidade Federal de Goiás (EA/UFG), com a finalidade de se calibrar a vazão, em função do desnível entre o nível da água na caixa de controle de nível e o contato com o solo no interior da calha. Esta calibração serviu também para o ajuste de detalhes de funcionamento do equipamento.

A calibração foi realizada pelo método direto, medindo-se o tempo para que um mangote completasse, com água, um recipiente de volume predeterminado a diferentes desníveis (carga hidráulica). Os dados obtidos foram compilados, chegando à equação de vazão, em função da altura (Eq. 1).

$$
\mathrm{Q}=0,0005 \mathrm{H}+0,0002
$$

em que:

$$
\mathrm{Q} \text { - vazão, } \mathrm{m}^{3} \mathrm{~s}^{-1}, \mathrm{e}
$$

$\mathrm{H}$ - diferença de nível, $\mathrm{m}$

Após a calibração e ajuste de detalhes do equipamento, realizaram-se testes de escoamento em solos de diferentes estradas: $\left(\mathrm{E}_{1}\right)$ da Escola de Agronomia para a fábrica de ração da Escola de Veterinária da UFG, altitude de $710 \mathrm{~m}$, latitude S $16^{\circ} 35^{\prime} 33$ ' e longitude O 49 16' 51'”; ( $\left.\mathrm{E}_{2}\right)$ estrada vicinal Doverlândia/Baliza, no município de Baliza, GO, altitude de $551 \mathrm{~m}$, latitude $\mathrm{S} 16^{\circ} 29^{\prime} 35^{\prime}$ ', longitude O $52^{\circ}$ 23' 54"'; $\left(\mathrm{E}_{3}\right)$ estrada GO-194, trecho Doverlândia/Rio Araguaia, altitude $518 \mathrm{~m}$, latitude $\mathrm{S} 16^{\circ} 42^{\prime} 37,5^{\prime}$, longitude $\mathrm{O}$ $52^{\circ} 20^{\prime \prime} 0,50$ "; $\left(\mathrm{E}_{4}\right)$ estrada vicinal, município de Morrinhos, GO altitude $758 \mathrm{~m}$, latitude $\mathrm{S} 17^{\circ} 41^{\prime} 59,5^{\prime}$, longitude $\mathrm{O} 49^{\circ}$ 07' 23,9"; $\left(\mathrm{E}_{5}\right)$ estrada vicinal, município de Morrinhos, GO, altitude $710 \mathrm{~m}$, latitude $\mathrm{S} 17^{\circ} 41^{\prime} 24,9^{\prime}$ ', longitude $\mathrm{O} 49^{\circ} 06^{\prime}$ 24,9"; $\left(\mathrm{E}_{6}\right)$ estrada vicinal, município de Morrinhos, GO, altitude $710 \mathrm{~m}$, latitude $\mathrm{S} 17^{\circ} 41^{\prime} 24,9^{\prime}$ ' e longitude $\mathrm{O} 49^{\circ} 06^{\prime}$ 49,7".

Para realização dos testes em campo, o equipamento foi instalado diretamente no canal de cada estrada, sendo o sistema de derivação e controle de nível posicionado a montante, de modo que todo o processo pudesse ser realizado por gravidade. Para a condução da água até o sistema de derivação utilizou-se, como reservatório, caminhão tanque (pipa) com capacidade para 15.000 L de água e caixa d'água de 2.500 L.

Os valores de declividade do terreno na parte interna à calha e o raio hidráulico, foram determinados para cada instalação, sendo a declividade medida diretamente em campo. Obteve-se o coeficiente de rugosidade hidráulica de Manning (n), da literatura, para a condição que mais se aproximava daquela observada na superfície do canal em cada situação; fixou-se, então, $\mathrm{n}=0,020$.

Antes da realização dos testes se aplicou uma lâmina de escoamento de $0,5 \mathrm{~L} \mathrm{~s}^{-1}$, durante $10 \mathrm{~s}$, visando à remoção de sedimentos soltos sobre a superfície da área a ser ensaiada. As vazões foram alteradas, de maneira crescente, por meio da abertura de registros de forma seqüencial $(1,2,3,4$ e 5 registros). Os tempos de aplicação para cada vazão foram determinados previamente de modo a completar uma caixa do sistema de armazenamento. Este sistema de armazenamento funcionou com cada caixa coletora recebendo sedimentos relativos a uma vazão aplicada, cuja operação de mudança foi feita manualmente. Estabeleceu-se o instante de mudança de coletor por meio de lançamento de um flutuador na calha de escoamento, no exato momento de troca de vazão. Com a chegada do flutuador na caixa coletora, imediatamente era realizada a mudança para a outra, de forma repetida e ordenada.

Posterior à realização de cada teste, a água coletada nas caixas do sistema de armazenamento foi filtrada, procedimento este realizado individualmente para cada caixa do sistema de armazenamento, visando à coleta dos sedimentos. Desta forma se obtiveram quantidades de solo erodido para cada tensão e tempo de aplicação utilizado. A filtragem foi realizada através de peneira malha $200(0,074 \mathrm{~mm})$, possibilitando a coleta dos dados de campo para serem compilados.

Todo o material erodido coletado na peneira $0,074 \mathrm{~mm}$ foi armazenado em recipiente próprio, conduzido ao laboratório da Escola de Agronomia da UFG, para ser desagregado e novamente filtrado pela mesma peneira, deixando-se apenas o material com diâmetros superiores a $0,074 \mathrm{~mm}$, o qual foi conduzido, em seguida, à estufa, por um período mínimo de $24 \mathrm{~h}$, a temperatura de $105^{\circ} \mathrm{C}$; posteriormente, ele foi pesado em balança de precisão de $0,0001 \mathrm{~g}$.

Para cada canal de estrada onde se obtiveram amostras com o simulador de escoamento superficial coletou-se, separadamente, material do solo local que, posteriormente, foi levado ao laboratório da Escola de Engenharia Civil da UFG. Com este material foi determinada a curva granulométrica por sedimentação obtendo-se a textura e classe textural dos solos de cada estrada nos locais de teste (Tabela 1).

Tabela 1. Textura referente aos solos de cada estrada nos locais

\begin{tabular}{|c|c|c|c|c|}
\hline \multirow{2}{*}{ Estrada } & Argila & Silte & Areia & \multirow{2}{*}{ Classe textural } \\
\hline & & $(\%)$ & & \\
\hline E1(Goiânia) & 22 & 8 & 68,3 & Franco arenoso \\
\hline E2 (Baliza) & 5 & 8 & 87 & Arenoso \\
\hline E3 (Doverlândia) & 33 & 34 & 33 & Franco argiloso \\
\hline E4 (Morrinhos) & 38 & 14 & 45,7 & Argila arenosa \\
\hline E5 (Morrinhos) & 18 & 17 & 62,6 & Franco arenoso \\
\hline E6 (Morrinhos) & 30 & 10 & 60 & Franco argilo arenoso \\
\hline
\end{tabular}
de realização dos testes

A estimativa do total de solo erodido foi estabelecida por regra de três direta, entre o percentual de material retido na peneira $0,074 \mathrm{~mm}$, determinado pela curva granulométrica e o total retido nesta mesma peneira pelo laboratório com os dados de campo. 
Através da vazão, seção da calha e da declividade definida em cada teste, em que a tensão aplicada pelo escoamento foi uma variável em função da vazão de escoamento superficial, determinou-se a tensão cisalhante pela Eq. 2 de Chow (1959).

$$
\tau_{\mathrm{e}}=\frac{\gamma \mathrm{RhS}}{0,102}
$$

em que:

$\tau_{\mathrm{e}}$ - tensão provocada pelo escoamento, $\mathrm{Pa}$

$\gamma$ - peso específico da água, $\mathrm{kgf} \mathrm{m}^{-3}$

$\mathrm{Rh}$ - raio hidráulico, $\mathrm{m}$

$\mathrm{S}$ - declividade do canal, $\mathrm{m} \mathrm{m}^{-1}$

Tendo em vista que a tensão provocada pelo escoamento em canais não ocorre de maneira uniforme em toda a seção transversal, considerou-se apenas a tensão máxima, a qual provoca as maiores desagregações de solo. Desta forma, utilizando-se a equação de Manning, o valor do $R_{h}$ foi substituído pela profundidade de escoamento y, conforme equações 3 e 4, enquanto a unidade de saída foi transformada para Pascal (Pa), (Eq. 5).

$$
\mathrm{Q}=\frac{1}{\mathrm{n}} \mathrm{AR}_{\mathrm{h}}{ }^{2 / 3} \mathrm{~S}^{1 / 2}
$$

em que:

$\mathrm{Q}$ - vazão, $\mathrm{m}^{3} \mathrm{~s}^{-1}$

$\mathrm{n}$ - coeficiente de rugosidade

A - área de escoamento, $\mathrm{m}^{2}$

$\mathrm{R}_{\mathrm{h}}$ - raio hidráulico, $\mathrm{m}$

$\mathrm{S}$ - gradiente hidráulico ou desnível do canal, $\mathrm{m} \mathrm{m}^{-1}$

$$
\frac{y^{5 / 3}}{(L+2 y)^{2 / 3}}=\frac{Q n}{S^{1 / 2} L^{5 / 3}}
$$

sendo: y corresponde à profundidade de escoamento, $\mathrm{m}, \mathrm{e} \mathrm{L}$ à largura da calha, $\mathrm{m}$

$$
\tau_{\mathrm{E}}=\frac{\gamma \mathrm{yS}}{0,102}
$$

Determinadas a tensão de cisalhamento para cada vazão de escoamento aplicada e a desagregação de solo ocorrida no intervalo em que o canal esteve sujeito a cada tensão, geram-se gráficos que relacionam essas informações. A erodibilidade do solo do canal foi obtida por meio da determinação da inclinação da curva de perda de solo enquanto se obteve a tensão crítica de cisalhamento por meio de prolongamento da curva de desagregação de solo até o eixo de desagregação zero, conforme apresentado na Figura 1.

\section{RESULTADOS E DISCUSSÃO}

Apresentam-se, na Tabela 2, os resultados de desagregação de solo e da tensão de cisalhamento em função da vazão de entrada em tempo determinado para cada estrada em que foi executado teste de campo. Os valores de desagregação de solo variaram com cada solo testado face às características do

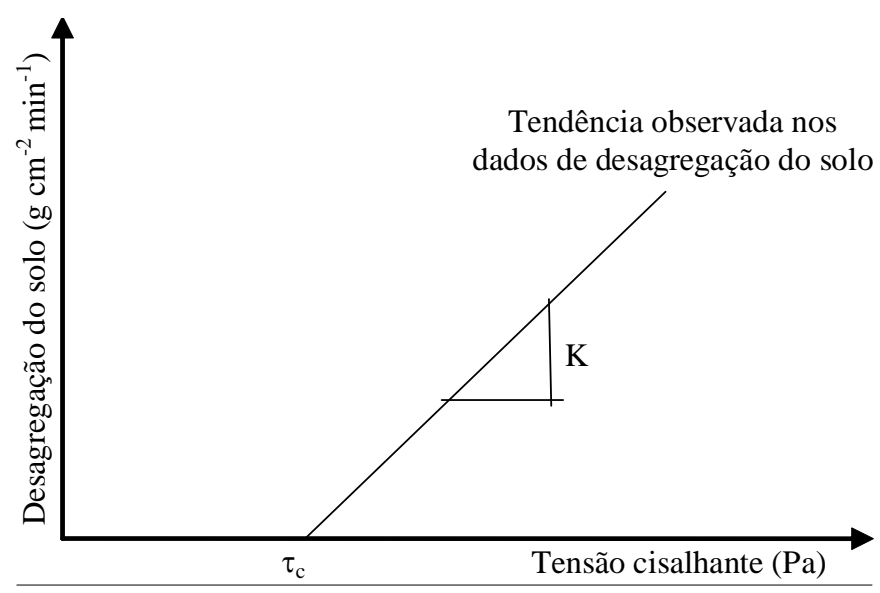

Figura 1. Representação esquemática da forma de obtenção da erodibilidade (K) e da tensão crítica de cisal hamento do solo $\left(\mathrm{t}_{\mathrm{c}}\right)$

\begin{tabular}{|c|c|c|c|c|}
\hline Estrada & $Q\left(m^{3} s^{-1}\right)$ & $T(\min )$ & D.S. $\left(\mathrm{g} \mathrm{cm}^{-2} \mathrm{~min}^{-1}\right)$ & $\tau(\mathrm{Pa})$ \\
\hline \multirow{5}{*}{ E1 (Goiânia) } & 0,0007250 & 6,900 & 0,000061500 & 1,61 \\
\hline & 0,0014500 & 3,450 & 0,000673000 & 2,51 \\
\hline & 0,0021750 & 2,300 & 0,002770000 & 3,26 \\
\hline & 0,0029000 & 1,720 & 0,006490000 & 3,94 \\
\hline & 0,0036250 & 1,380 & 0,010800000 & 4,57 \\
\hline \multirow{5}{*}{ E2 (Baliza) } & 0,0007080 & 7,070 & 0,001301070 & 1,75 \\
\hline & 0,0014150 & 3,530 & 0,004263160 & 2,72 \\
\hline & 0,0021230 & 2,360 & 0,009567350 & 3,62 \\
\hline & 0,0028300 & 1,770 & 0,019275040 & 4,36 \\
\hline & 0,0035380 & 1,410 & 0,034990000 & 4,95 \\
\hline \multirow{5}{*}{ E3(Doverlândia) } & 0,0007075 & 7,067 & 0,010678800 & 3,14 \\
\hline & 0,0014150 & 3,534 & 0,031392900 & 4,85 \\
\hline & 0,0021225 & 2,356 & 0,075802400 & 6,27 \\
\hline & 0,0028300 & 1,767 & 0,142024900 & 7,55 \\
\hline & 0,0035375 & 1,413 & 0,374355400 & 8,73 \\
\hline \multirow{5}{*}{ E4 (Morrinhos) } & 0,0006525 & 7,660 & 0,003270983 & 3,56 \\
\hline & 0,0013050 & 3,830 & 0,009360765 & 5,47 \\
\hline & 0,0019575 & 2,550 & 0,019643513 & 7,07 \\
\hline & 0,0026100 & 1,920 & 0,032528430 & 8,50 \\
\hline & 0,0032625 & 1,530 & 0,049857525 & 9,81 \\
\hline \multirow{5}{*}{ E5 (Morrinhos) } & 0,0006900 & 7,250 & 0,000456090 & 4,21 \\
\hline & 0,0013800 & 3,620 & 0,002477100 & 6,48 \\
\hline & 0,0020700 & 2,420 & 0,014283000 & 8,37 \\
\hline & 0,0027600 & 1,810 & 0,019678800 & 10,06 \\
\hline & 0,0034500 & 1,450 & 0,028534950 & 11,61 \\
\hline \multirow{5}{*}{ E6 (Morrinhos) } & 0,0006415 & 7,790 & 0,000299367 & 3,05 \\
\hline & 0,0012830 & 3,900 & 0,003037813 & 4,67 \\
\hline & 0,0019245 & 2,600 & 0,006849565 & 6,00 \\
\hline & 0,0025660 & 1,950 & 0,017145295 & 7,18 \\
\hline & 0,0032075 & 1,560 & 0,029281371 & 8,27 \\
\hline
\end{tabular}

Tabela 2. Valores de vazão, tempo de aplicação de água, desagregação de solo e tensão de cisalhamento obtidos para cada estrada

$\mathrm{Q}=$ Vazão; $\mathrm{T}=$ Tempo; DS = Desagregação de Solo; $\mathrm{t}_{\mathrm{E}}=$ Tensão de cisalhamento do solo 
escoamento superficial no canal, definidas pelo tipo de solo e da estrada do local.

De posse dos resultados de desagregação de solo e tensão de cisalhamento para cada estrada, determinou-se a erodibilidade $(\mathrm{K})$ e a tensão crítica de cisalhamento $\left(\mathrm{t}_{\mathrm{c}}\right)$ cujos resultados se encontram representados na Figura 2 e na Tabela 3 .

Tabela 3. Valores de erodibilidade e tensão crítica de cisalhamento para diferentes solos de estradas não pavimentadas, em função das variações de tempo, vazão e desagregação de solo

\begin{tabular}{|c|c|c|}
\hline Estrada & $\mathrm{K}\left(\mathrm{g} \mathrm{cm}^{-2} \mathrm{~min}^{-1} \mathrm{~Pa}^{-1}\right)$ & $\tau_{\mathrm{c}}(\mathrm{Pa})$ \\
\hline El(Goiânia) & 0,0036 & 2,03 \\
\hline E2 (Baliza) & 0,0098 & 2,08 \\
\hline E3 (Doverlândia) & 0,0582 & 3,93 \\
\hline E4 (Morrinhos) & 0,0073 & 3,78 \\
\hline E5 (Morrinhos) & 0,0039 & 4,87 \\
\hline E6 (Morrinhos) & 0,0054 & 3,74 \\
\hline
\end{tabular}

$\mathrm{K}=$ Erodibilidade; $\tau_{\mathrm{c}}=$ Tensão crítica de cisalhamento

Na Figura 2 se observa que a melhor correlação para os resultados seria exponencial; no entanto, isto caracterizaria um valor de erodibilidade dinâmico, dificultando sua aplicação prática principalmente em dimensionamento de projetos para implantação de estradas; realizou-se, então, um ajuste linear, de forma que a erodibilidade pudesse ser considerada como valor único para cada solo.

Em cada solo de estrada diferente foi possível verificar formas variadas de desagregação de solo, em função da variação do tempo e da vazão aplicada caracterizando que, além da declividade de cada situação, as propriedades físico-químicas são determinantes quanto ao seu comportamento pe- rante os processos erosivos; essas propriedades indicaram variações próprias e correlacionadas de acordo com a sua classe textural, mostrando maior ou menor grau de susceptibilidade a erosão.

As estradas nas quais se realizaram os testes, apresentavam elevada quantidade de material solto e de pouca estrutura, indicando a presença de grandes quantidades de silte e areia, principalmente em $E_{1}, E_{2}$ e $E_{3}$. Apesar do trabalho de coleta de dados ter sido realizado em período seco, observaram-se indícios de erosão, tanto nas margens das estradas como nas áreas de entorno (Figura 3).

As Figuras 3 e 4 indicam que o processo de erosão hídrica no canal da estrada foi bastante intenso visto que o tráfego, após ser impedido, foi deslocado para outra estrada ao



Figura 3. Equipamento instalado na estrada D overlândia-Baliza, no município de Baliza, GO, mostrando a estrada deslocada de seu eixo original devido ao al to índice de erosão
A.

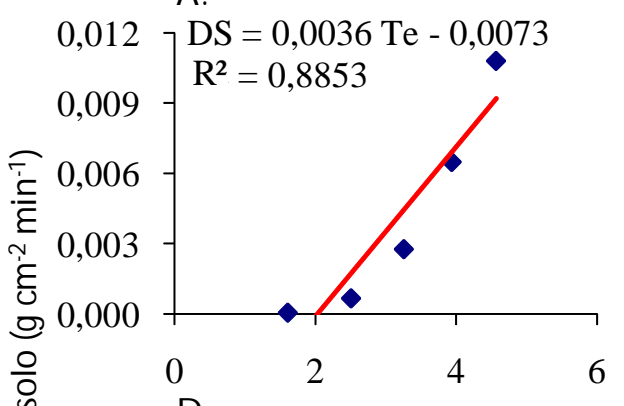

D.

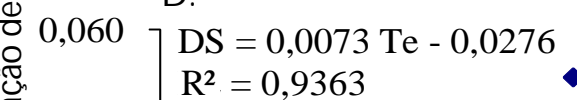

$\mathrm{R}^{2}=0,9363$

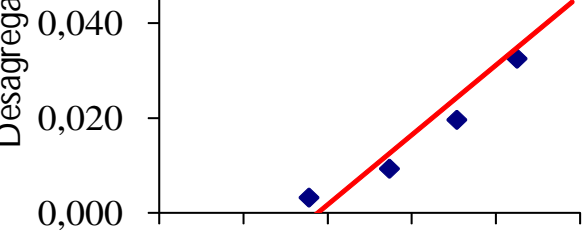

$\begin{array}{llllll}0 & 2 & 4 & 6 & 8 & 10\end{array}$
B.
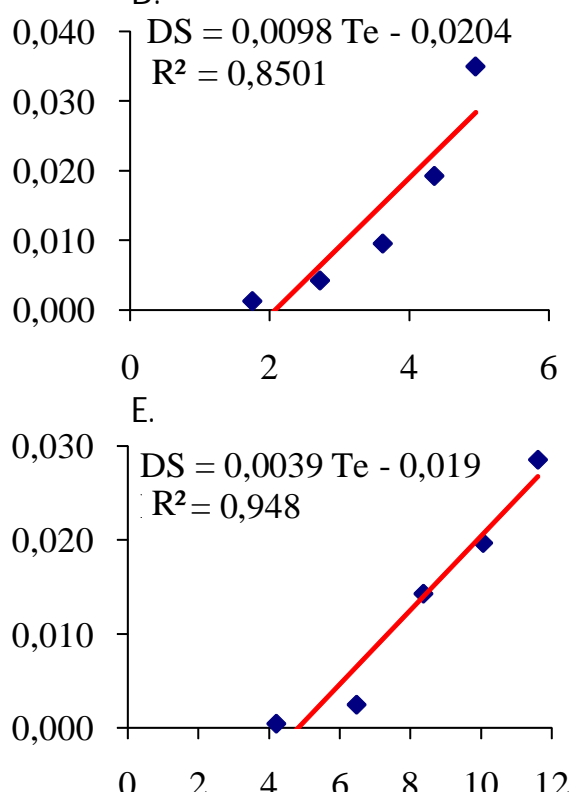

Tensão de Cisalhamento $(\mathrm{Pa})$
C.

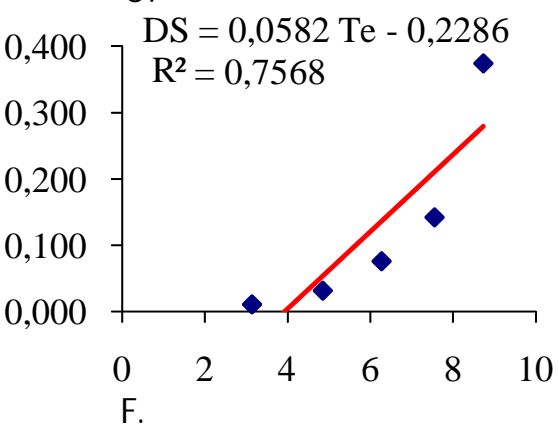

$0,040] \mathrm{DS}=0,0054 \mathrm{Te}-0,0202$

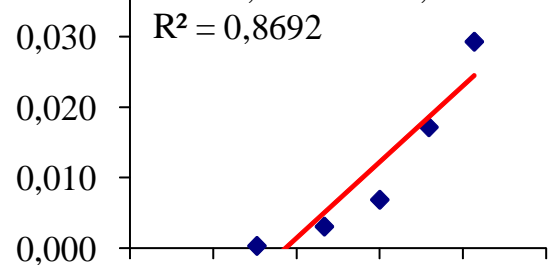

$\begin{array}{llllll}0 & 2 & 4 & 6 & 8 & 10\end{array}$

Figura 2. Curva de ajuste para as estradas $E_{1}-$ Goiânia $(A) ; E_{2}$ - Baliza (B); $E_{3}$ - Doverlândia (C); $E_{4}-$ Morrinhos (D), $E_{5}-M$ orrinhos (E) e $E_{6}-M o r r i n h o s ~(F)$ 


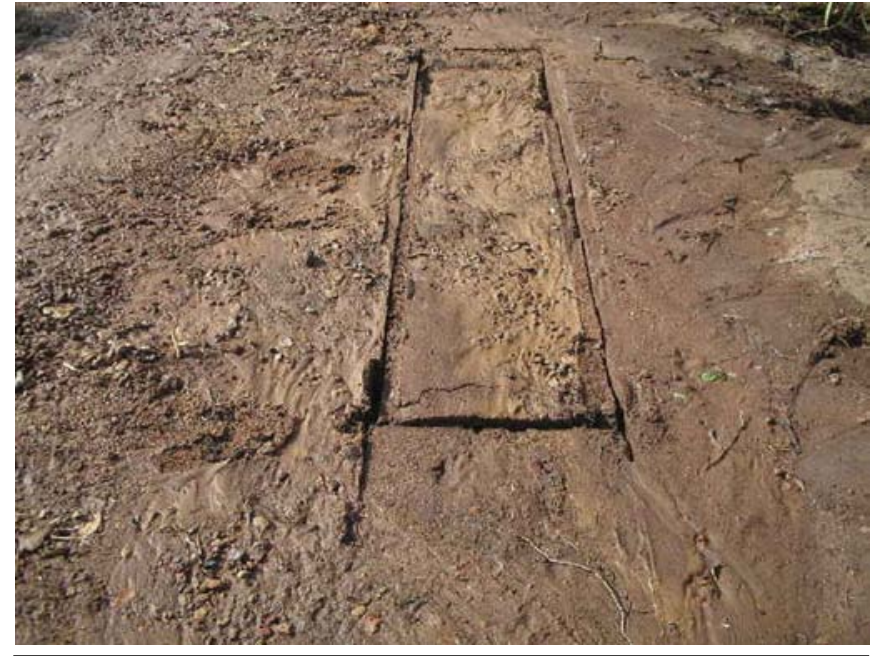

Figura 4. Local de instalação da calha posterior à realização dos testes, Município de Baliza, GO, com evidências do material erodido

lado, onde o teste com o simulador de escoamento superficial foi realizado. A Figura 4 justifica os valores de desagregação de solo e do coeficiente de erodibilidade encontrados para $\mathrm{E}_{2}$.

Em sua maioria, os valores de erodibilidade encontrados se apresentam inferiores àqueles obtidos na literatura para solos de regiões agrícolas, porém em conformidade com obtidos na literatura para condições de estradas. Morfin et. al (1996), obtiveram erodibilidade de 0,0036 $\left(\mathrm{g} \mathrm{cm}^{-2} \mathrm{~min}^{-1} \mathrm{~Pa}^{-1}\right)$ para solos siltosos sob condições de estrada, coincidindo com o valor encontrado neste trabalho para a condição $\mathrm{E}_{1}$; este valor, no entanto, correspondeu ao valor encontrado por Morfin et al. (1996) para a condição mais crítica e Griebeler et al. (2005b) constataram, para Latossolo argiloso, em Viçosa, MG, valor de erodibilidade de $0,00109 \mathrm{~g} \mathrm{~cm}^{-2} \mathrm{~min}^{-1} \mathrm{~Pa}^{-1}$.

Os valores encontrados sugerem, quando comparados com a literatura, elevados riscos de ocorrência de erosão, caso não sejam tomadas medidas adequadas de controle e monitoramento para o sistema de drenagem destas estradas. Para a estrada $\mathrm{E}_{2}$, localizada em solo com elevada quantidade de areia e $\mathrm{E}_{3}$, situada em corte diretamente sobre o horizonte $\mathrm{C}$, os valores de erodibilidade se mostram bastante elevados indicando que cuidados especiais devem ser tomados para reduzir a ocorrência de erosão, tornando-se necessários trabalhos com revestimento primário e drenagem adequada. Recomendam-se, para a drenagem de estradas nesses solos se recomendam estudos sobre espaçamentos entre os canais desaguadouros, bacias de acumulação para armazenamento do volume escoado e revestimento primário.

Os resultados encontrados para $\mathrm{E}_{1}, \mathrm{E}_{4}, \mathrm{E}_{5}$ e $\mathrm{E}_{6}$ mostraram valores menores de erodibilidade, indicando solos mais resistentes a erosões e, conseqüentemente, estradas com melhores condições de manutenção e conservação não se dispensando, no entanto, projetos adequados para drenagem e condução da água.

Em alguns solos os coeficientes de erodibilidade foram relativamente altos, indício de serem bastante susceptíveis a erosão, porém, com valores de tensão crítica de cisalhamentos também altos, sinalizando resistência ao início do proces- so erosivo; no entanto, após o início do processo se desagregam em taxas consideravelmente elevadas.

\section{CONCLUSÕES}

1. Os valores de erodibilidade e de tensão crítica de cisalhamento mostraram-se bastante variáveis.

2. Os coeficientes de erodibilidade obtidos nas diferentes estradas mostraram-se elevados, sugerindo altos riscos de erosão.

3. Maiores índices de erodibilidade foram obtidos em solos com maiores teores de silte e areia.

4. Os resultados indicam a necessidade de estudos e projetos individualizados para as diferentes estradas.

\section{LITERATURA CITADA}

Amorim, R. S. S.; Silva, D. D. da; Pruski, F. F.; Matos, A. T. Influência da declividade do solo e da energia cinética de chuvas simuladas no processo de erosão entre sulcos. Revista Brasileira de Engenharia Agrícola e Ambiental, v.5, n.1, p.124-130, 2001.

Campos, F. da. S. de.; Alves, M. C. Resistência à penetração de um solo em recuperação sob sistemas agrosilvopastoris. Revista Brasileira de Engenharia Agrícola e Ambiental, v.10, n.3, p.759-764, 2006.

Chow, V. T. Open channel hydraulics. New York: McGraw-Will Book Company Inc. 1959. 680p.

Corrêa, C. M. C.; Malinovski, J. R.; Roloff, G. Bases para planejamento de rede viária em reflorestamento no sul do Brasil. Floresta, v.36, n.2, p.277-286, 2006.

Griebeler, N. P.; Pruski, F. F.; Mejl, H. U.; Silva, D. D. da; Oliveira, L. F. C. de. Equipamento para determinação da erodibilidade e tensão crítica de cisalhamento do solo em canais de estradas. Revista Brasileira de Engenharia Agrícola e Ambiental, v.9, n.2, p.166-170, 2005a.

Griebeler, N. P.; Pruski, F. F.; Silva, A. M. J.; Ramos, M. M.; Silva, D. D. Modelo para a determinação do espaçamento entre desaguadouros em estradas não pavimentadas. Revista Brasileira de Ciência do Solo, v.29, p.397-405, n.3, 2005 b.

Moreti, D.; Carvalho, M. P.; Mannige, A. R.; Medeiros, L. R. Importantes características de chuva para a conservação de solo e da água no Município de São Manuel (SP). Revista Brasileira de Ciência do Solo, v.1, n.1, p.713-726, 2003.

Morfin, S.; Elliot, B. W.; Foltz, R.; Miller, S., Predicting effects of climate, soil, and topography on road erosion with the WEPP model. ASAE Annual International Meeting 1996, St. Joseph. Anais...Missouri: ASAE. 1996. 12p.

Nogami, J. S.; Villibor, D. F. Pavimentação de baixo custo com solos lateríticos. São Paulo: Villibor, 1995. 240p.

Panachuki, E.; Alves Sobrinho, T.; Vitorino, A. C. T.; Carvalho, D. F. de.; Urchei, M. A. Parâmetros físicos do solo e erosão hídrica sob chuva simulada, em área de integração agriculturapecuária. Revista Brasileira de Engenharia Agrícola e Ambiental, v.10, n.2, p.261-268, 2006. 